\title{
Biomass and Stored Carbohydrate Compensation after Above-Ground Biomass Removal in a Perennial Herb: Does Environmental Productivity Play a Role?
}

\author{
Vít Latzel • Štěpán Janeček • Tomáš Hájek • \\ Jitka Klimešová
}

(C) Institute of Botany, Academy of Sciences of the Czech Republic 2013

\begin{abstract}
Many plant species are able to tolerate severe disturbance leading to removal of a substantial portion of the body by resprouting from intact or fragmented organs. Resprouting enables plants to compensate for biomass loss and complete their life cycles. The degree of disturbance tolerance, and hence the ecological advantage of damage tolerance (in contrast to alternative strategies), has been reported to be affected by environmental productivity. In our study, we examined the influence of soil nutrients (as an indicator of environmental productivity) on biomass and stored carbohydrate compensation after removal of aboveground parts in the perennial resprouter Plantago lanceolata. Specifically, we tested and compared the effects of nutrient availability on biomass and carbon storage in damaged and undamaged individuals. Damaged plants of $P$. lanceolata compensated neither in terms of biomass nor overall carbon storage. However, whereas in the nutrient-poor environment, root total non-structural carbohydrate concentrations (TNC) were similar for damaged and undamaged plants, in the nutrient-rich environment, damaged plants had remarkably higher TNC than undamaged plants. Based on TNC allocation patterns, we conclude that tolerance to disturbance is promoted in more productive environments, where higher photosynthetic efficiency allows for successful replenishment of carbohydrates. Although plants under nutrient-rich conditions did not compensate in terms of biomass or seed production, they entered winter with higher content of carbohydrates, which might result in better performance in the next
\end{abstract}

V. Latzel ( $ه)$

Institute of Botany, Academy of Sciences of the Czech Republic

Zámek 1, CZ-252 43 Průhonice, Czech Republic

e-mail: latzel@ips.unibe.ch

V. Latzel

Institute of Plant Sciences, University of Bern

Altenbergrain 21, CH-3013 Bern, Switzerland

Š. Janeček • T. Hájek · J. Klimešová

Institute of Botany, Academy of Sciences of the Czech Republic

Dukelská 135, CZ-379 82 Třeboň, Czech Republic 
growing season. This otherwise overlooked compensation mechanism might be responsible for inconsistent results reported from other studies.

Keywords Compensation - Disturbance $\cdot$ HPLC $\cdot$ Non-structural carbohydrate storages . Nutrients $\cdot$ Photosynthesis $\cdot$ Plantago lanceolata $\cdot$ Resprouting

\section{Introduction}

As sedentary organisms, plants cannot move away from environmental perturbations or disturbance events. Among other factors, human and large herbivore activity or fire can lead to loss of all aboveground organs or fragmentation of the plant body. Nevertheless, upon confronting such dramatic events, some plant species can limit their vulnerability by resprouting from intact organs or fragments. The abilities of a plant to resprout, potentially regain original biomass levels and eventually produce seed are affected by factors including mineral nutrient availability, plant ontogeny and phenology, damage severity, and competition as well as the plant's pool of available meristems and storage carbohydrates (Ferraro and Oesterheld 2002; Huhta et al. 2003; Martínková et al. 2004; Latzel and Klimešová 2009; Latzel et al. 2011; Clarke et al. 2013). Of these, mineral nutrient availability has been thus far the most studied (e.g. Clarke et al. 2005; Martínková et al. 2008; Suwa and Maherali 2008; Latzel and Klimešová 2009; Banta et al. 2010; Bartoš et al. 2011, see also "limiting resource framework" below). Neither reserve meristem availability nor storage carbohydrate abundance has received nearly as much attention as mineral availability even though both play crucial roles in influencing how plants succeed in overcoming damage. This is probably due to the relative ease of assessing plant biomass and seed production responses to damage under different levels of soil nutrient availability in contrast to the difficulty of evaluating bud banks (Dalgleish and Hartnett 2006) or analysing carbohydrate content (Richards and Caldwell 1985; Sosnová and Klimešová 2009; Tolsma et al. 2010; Janeček et al. 2011). Since carbon and nutrient economies are tightly connected during plant ontogeny (Janeček et al. 2014, this issue), the lack of studies evaluating damage responses in conjunction with assessments of stored carbohydrates under different levels of nutrient availability prevents us from getting a complete picture of regenerative mechanisms and strategies.

According to the "limiting resource framework" proposed by Banta et al. (2010), the limiting factors for resprouting in response to apical meristem damage are the availability of nutrients and/or meristems (Banta et al. 2010). We suggest modifying this conceptual framework to include the role of carbohydrates in tolerance to disturbance. In our model (Fig. 1), we emphasize three steps distinguishable during the course of plant growth after damage: resprouting, biomass compensation and compensatory seed production. Whereas resprouting leads to reduction of carbohydrate reserves, regrown biomass enables refilling of storage organs, and seed production, again, requires carbohydrate consumption. Seed production, the meristem pool, and stored carbohydrates should all be jointly taken into account as a measure of compensation rate in a perennial plant because they affect future performance of plants during spring regrowth (carbohydrates and bud bank) and during generative regeneration (seeds; Fig. 1). Nonetheless, the majority of studies engaged in 


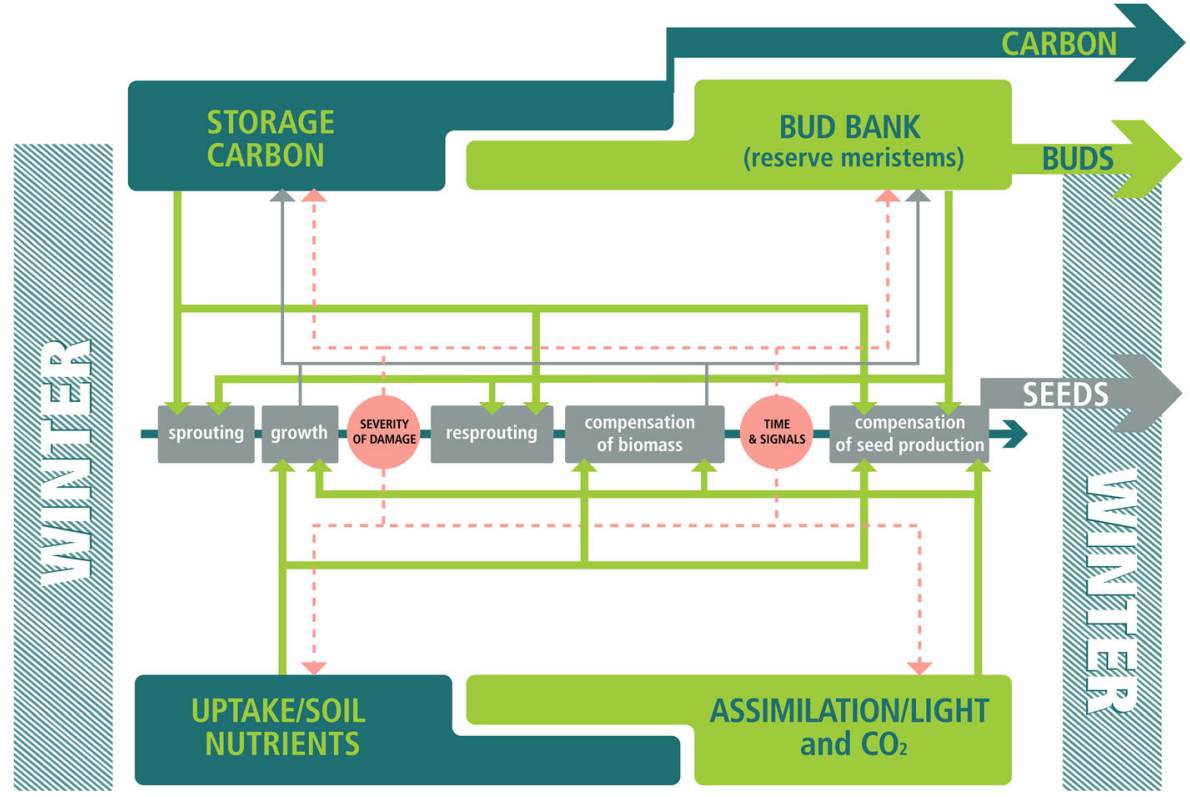

Fig. 1 Course of plant growth (interrupted by damage) between two consecutive winters (dashed boxes) showing internal sources (bud bank/meristems) and carbon storage, and external resources (carbon and soil nutrients). Thick arrows - positive effect on plant growth, solid thin arrows - refilling of reserves at the expense of growth, dashed thin arrows - external force affecting assimilation, nutrient uptake and storage building. Carbon storage and dormant meristems are needed for the onset of plant re-growth after winter and for resprouting after damage whereas nutrient uptake and assimilation are crucial for further growth, biomass compensation and refilling of storage. Carbon storage is not involved in biomass compensation in our model because it has been shown that stored carbohydrates are utilized largely during the resprouting phase, which enables the formation of new photosynthetic tissue. Compensatory growth is driven by products of current photosynthesis, not by storage (see e.g. Richards and Caldwell 1985). Compensatory seed production depends not only on previous growth and storage refilling but also on signals triggering flowering such as day length or body size and the time available for flowering limited by the end of growing season. The large arrows represent investments in a future generation (seeds) and persistence of a plant to the following growing season (storage carbon and bud bank). We focused on relevant connexions and therefore omitted some possible but less-important effects to maintain clarity of the schematic

compensatory re-growth of damaged plants usually evaluate only biomass and/or seed production, leaving carbon storage aside. However, carbon storage does not only affect regeneration outcomes of damaged plants but is also a result of compensatory re-growth, thus representing an important part of plant strategy in coping with future demands (Canadell and López-Soria 1998; Schutz et al. 2009).

In order to improve our understanding of plants' compensatory responses, we focused on carbon storage, biomass, and seed production of damaged and undamaged plants grown under conditions varying in nutrient availability. In our pot experiment on the perennial species Plantago lanceolata, we hypothesized that damaged plants growing in surplus nutrient conditions would be better able to use accumulated carbohydrates and more successful in biomass compensation and seed production than damaged plants from nutrient limited conditions. The latter plants, we predicted, would have less regrowth and seed production, and would instead accumulate carbohydrates due to increased allocation of limited resources to storage organs, 
which is usually reported to occur in stressful environments (White 1973; Hutchings and John 2004; Puijalon et al. 2008; Clarke et al. 2013).

\section{Material and Methods}

Plantago lanceolata was selected as a representative of perennial herbs capable of resprouting after severe damage. It is a protogynous, self-incompatible, hemicryptophyte perennial species with monopodial, short stems, leaf rosettes and a taproot, which may be replaced by adventitious roots in older plants. The species is widespread in Europe, where it is found on a wide range of soil types. Plantago lanceolata regenerates vegetatively from roots after damage (Klimešová and Klimeš 2006) but also produces a considerable number of seeds (Latzel and Klimešová 2009). In this species, carbohydrates are stored mainly in the roots (Janeček et al. 2011).

\section{Plant Material and Study Design}

The experiment ran from spring 2009 to late summer 2010. To account for potential genetic variation among plants, populations of four genotypes of $P$. lanceolata were considered. Genotypes were obtained by clonal replication of 32 daughter plants from each of four adult plants from a natural population under nearly natural conditions in the immediate vicinity of the Institute of Botany of the Academy of Science of the Czech Republic in Třeboň, Czech Republic. Replication was carried out by direct organogenesis from leaf segments using a technique developed by Budzianowska et al. (2004).

Each replicate plant was planted in a separate pot $(15 \times 15 \times 20 \mathrm{~cm})$ filled with a mixture of a commercial soil substrate and sand ( $2: 3$ ratio). All pots were placed in shallow pits filled with sand to avoid frost damage over winter and also to ensure homogenous conditions among individuals. Equal numbers of plants of all four genotypes were randomly assigned to the following four treatments: nutrient-poor soil without damage ( $\mathrm{N}=8$ per genotype); nutrient-poor soil with severe damage $(\mathrm{N}=8$ per genotype); nutrient-rich soil without damage ( $\mathrm{N}=8$ per genotype) and nutrientrich soil with severe damage ( $\mathrm{N}=8$ per genotype). The nutrient-rich treatment consisted of regular application of a slow-release fertilizer (approximately $1.2 \mathrm{~g} \mathrm{~N}$, $0.3 \mathrm{~g} \mathrm{P}$ and $0.4 \mathrm{~g}$ Ca per plant per growing season). Nutrient-poor conditions involved no addition of fertilizer. Nutrient levels were chosen according to our previous experience with this species (e.g. Latzel et al. 2010; Latzel and Klimešová 2010). The soil and sand mixture without additional fertilization represents conditions where plants are still able to produce seeds but are apparently growing under suboptimal conditions. Such conditions should represent natural environments such as sandy nutrient-poor soils, in which P. lanceolata can sometimes be found. Conversely, addition of the fertilizer should mimic nutrient-rich soils of ruderal habitats, in which the species commonly grows. A severe disturbance event was inflicted on the plants at the beginning of May 2010 by clipping all aboveground parts, including the root base, leaving only the roots undamaged. Eleven out of the 128 individuals died during the study as a result of their failure to resprout after being subjected to damage or failure to overwinter. The presented measurements and analysis are therefore 
restricted to the remaining 117 individuals (30 undamaged and unfertilized plants, 29 undamaged and fertilized plants, 31 damaged and unfertilized plants, and 27 damaged and fertilized plants).

\section{Measurements}

The following measurements were recorded for all plants in 2010: number of spikes as a proxy for reproduction (the number of spikes produced by a plant is highly correlated with the number of seeds; Latzel et al. 2009), net photosynthetic $\mathrm{CO}_{2}$ assimilation rate (one leaf per plant; measured for three days in July 2010), total nitrogen content of the same leaves that had been subjected to photosynthesis measurements, above- and belowground dry biomass (plants were harvested during two days in September 2010 , dried at $80^{\circ} \mathrm{C}$ for at least 48 hours), and the content and composition of non-structural carbohydrates in main roots (taken during the harvest). Roots were carefully washed, main root samples taken for carbohydrate analyses were frozen to minus $75^{\circ} \mathrm{C}$ immediately after washing and stored deep frozen until analyzed. For carbohydrate storage, both the concentration (TNC) and total amount (OCS) stored in the roots were considered. The OCS was estimated by multiplying the carbohydrate concentration by root biomass.

The photosynthetic rate was measured using a portable Li-6400 (LICOR, USA) gas exchange system equipped with a standard $6 \mathrm{~cm}^{2}$ leaf chamber. The chamber conditions were the following: $\mathrm{CO}_{2}$ concentration of $400 \mathrm{ppm}$, leaf temperature of $25-30^{\circ} \mathrm{C}$, air flow rate of $500 \mu \mathrm{mol} / \mathrm{s}$ and mean relative humidity of $60 \%$. A built-in LED light source maintained saturating photosynthetically active radiation irradiance at $1,500 \mu \mathrm{mol} / \mathrm{m}^{2} / \mathrm{s}$. Each measurement took about $6 \mathrm{~min}$, which allowed stabilization of stomatal conductance and $\mathrm{CO}_{2}$ exchange.

Total nitrogen content in leaves was measured colourimetrically using a flow injection analysis (Foss Tecator AB, Sweden) by evaluating organic $\mathrm{N}$ mineralized to $\mathrm{NH}_{4}^{+}$.

Prior to carbohydrate analyses, all collected main roots were dried by lyophilization and ground in a ball mill. The following non-structural carbohydrate concentrations were analyzed: sorbitol, manitol, galactose, glucose, fructose, sucrose and raffinose family oligosaccharides (RFOs). These saccharides have been reported to be the main non-structural carbohydrates in Plantago lanceolata, whereas starch and fructans were not identified to be important storage compounds in the species (Janeček et al. 2011). Total non-structural carbohydrate concentration (TNC) represented the sum of all analyzed carbohydrates. The glucose, fructose, sorbitol, manitol and sucrose content was assessed using a highperformance anion exchange chromatography-pulsed amperometric detector (HPAE-PAD) with a Dionex ISC-3000 system. Carbohydrates were extracted into boiling ethanol, transferred into distilled water and separated in a CarboPac PA1 analytical column (Dionex, Prague, Czech Republic). RFOs were calculated as differences in ethanol-soluble carbohydrates (galactose, glucose, fructose and sucrose) before and after addition of a-galactosidase (Megazyme) to the ethanol extract. 


\section{Statistical Analyses}

We used a general linear model (GLM, EMS method) with a full factorial design to analyse the effects of damage and nutrient availability on growth, photosynthesis, leaf total nitrogen content and non-structural carbon storage attributes (root TNC and OCS). Damage history and nutrients were considered fixed effects whereas genotype identity was considered a random factor. If a significant interaction was found, Tukey's HSD post-hoc test was performed to detect significant differences between means of individual treatment combinations. To meet the assumptions of homoscedasticity and normality, all measured variables were log transformed prior to the analyses. All statistical analyses were performed using JMP statistical software (JMP 10.0; SAS Institute, Cary, NC, USA).

\section{Results}

\section{Growth Performance}

Higher nutrient supply resulted in higher growth and spike production of all plants (Table 1, Fig. 2a). However, genotypes differed in the degree to which they responded to nutrient levels (interaction $\mathrm{G} \times \mathrm{N}$, Table 1 ). Whereas all genotypes produced comparable biomass in the nutrient-rich environment, significant differences in biomass production were observed among genotypes under nutrient-poor conditions (post-hoc test, $P=0.008$ ).

Damaged plants were generally smaller and produced less spikes than undamaged individuals (Table 1, Fig. 2a). Both groups adjusted their growth similarly to changing nutrient availability (i.e. no significant interaction $\mathrm{N} \times \mathrm{D}$, Table 1, Fig. 1a). However, nutrient availability affected the root:shoot ratio and spike production differently in damaged and undamaged plants (Table 1, Fig. 2b,c). Whereas the R:S ratio was higher in damaged than in undamaged plants under nutrient-poor conditions, this ratio did not differ between the groups in nutrient-rich conditions (Fig. 2b). Regarding spike production, undamaged plants always created significantly more spikes than damaged plants. The difference was much greater in nutrient-rich conditions, however, as shown by the significant damage $\times$ nutrients interaction (Table 1, Fig. 2c).

\section{Non-Structural Carbohydrates}

The individual types of non-structural carbohydrate exhibited very similar patterns of variation among genotypes and treatments. For this reason, rather than presenting results individually for each of these carbohydrate types, only the root total nonstructural carbohydrate concentrations (TNC) and the overall carbon storage (OCS) results are presented.

Damaged plants had higher root TNC than those which had not been injured (D, Table 1, Fig. 2d), with the difference mainly attributable to differences between these two groups in the nutrient-rich environment $(\mathrm{N} \times \mathrm{D}$, Table 1, Fig. 2d, post-hoc test, $P<0.001)$. In the nutrient-poor environment, the root TNC concentrations did not differ between the two groups (post-hoc test, $P=0.999$ ). 


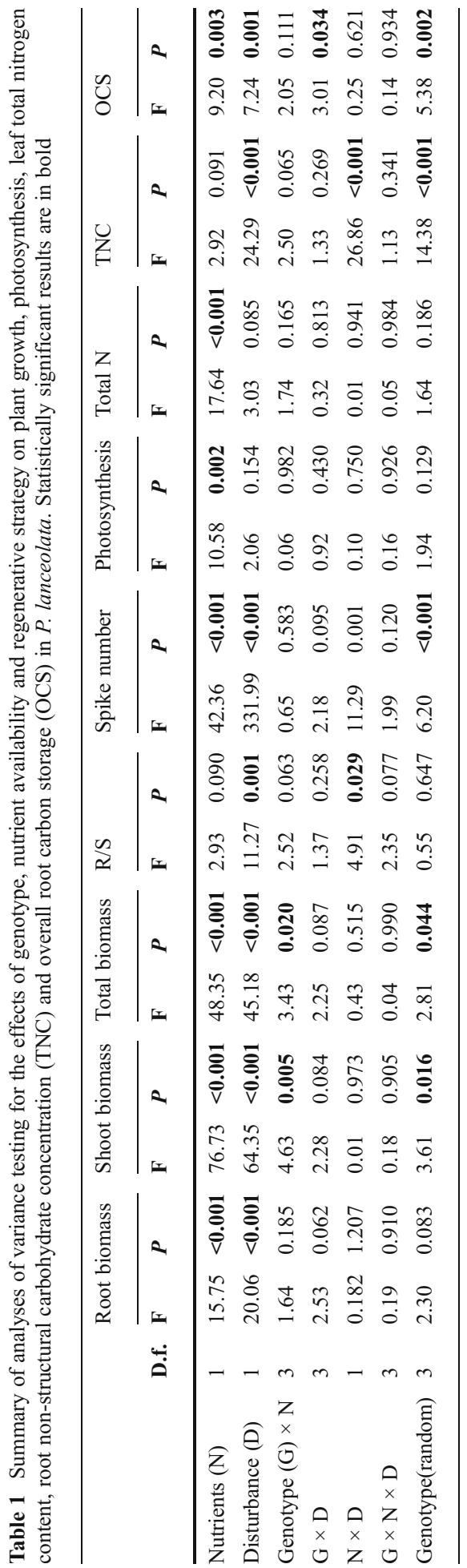


Fig. 2 Growth and storage allocation patterns in Plantago lanceolata in relation to different nutrient availability and disturbance regimes. a - Total biomass production; b - root-shoot ratio; $\mathbf{c}-$ spike production; $\mathbf{d}$ - concentration of carbohydrates in roots; $\mathbf{e}$ - carbon storage content in roots; $\mathbf{f}$ - photosynthesis; $\mathbf{g}-$ concentration of nitrogen in leaves. Mean values and SE are shown. In cases of significant interactions, post-hoc contrasts are shown: *** $-P<0.001$

Plants grown in the nutrient-rich environment had greater OCS than those grown in the nutrient-poor environment (Table 1, Fig. 2e). Undamaged plants had higher OCS than damaged plants, which reflects the overall higher growth of the former group (Table 1, Fig. 2e). Interestingly, the difference in OCS between the two groups was genotype-specific. Damaged plants had smaller OCS than undamaged plants in three out of four genotypes, but the opposite was found in one genotype.

\section{Photosynthesis and Total Leaf Nitrogen Content}

Both net photosynthetic capacity (Fig. 2f, Table 1) and leaf nitrogen content (Fig. 2g, Table 1) were affected by nutrients only, being lower under nutrient-poor conditions. Net photosynthesis was thus positively correlated with leaf nitrogen content (simple linear regression, $\left.R^{2}=0.327, P<0.0001\right)$.

\section{Discussion}

\section{Compensatory Growth in Relation to Soil Fertility}

Damaged plants of Plantago lanceolata were smaller, produced less spikes and stored less carbon in roots than undamaged plants at the end of the season in both nutrientpoor and nutrient-rich conditions. We, however, do not conclude that the degree of biomass and storage compensation, and hence the degree of tolerance to damage, was unaffected by nutrient availability. Rather, important differences were found between the plants grown under contrasting nutrient conditions in the effect of damage on carbohydrate concentrations, so this aspect of damage tolerance should not be overlooked. Unlike the plants grown under nutrient-poor conditions, in which the root TNC concentrations of damaged and control plants were similar, the concentrations in nutrient-rich conditions were significantly higher in damaged plants than undamaged plants (see Fig. 2d). Although the small number of spikes produced by damaged plants prevented a meaningful statistical analysis of the relationship between TNC and spike production, we can infer that carbohydrates were likely accumulated in damaged plants due to the absence of flowering and therefore the lack of an opportunity to invest carbohydrates in inflorescences. The absence of flowering in damaged plants could be a consequence of the lateness in the growing season by which plants had regrown and/or their small size (see also Sosnová and Klimešová 2009; Janeček et al. 2014, this issue). Consequently, although regenerated plants were reduced in size and seed production compared to the controls, the concentration of carbohydrates (TNC) in their roots was the same as (low availability of nutrients) or higher (high availability of nutrients) than in the control plants. These results imply that upregulation of photosynthesis in the nutrient-rich environment could have facilitated accumulation of carbohydrates in roots, although the more 
a

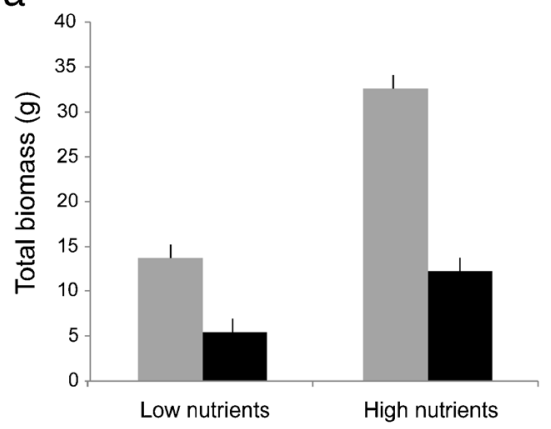

C
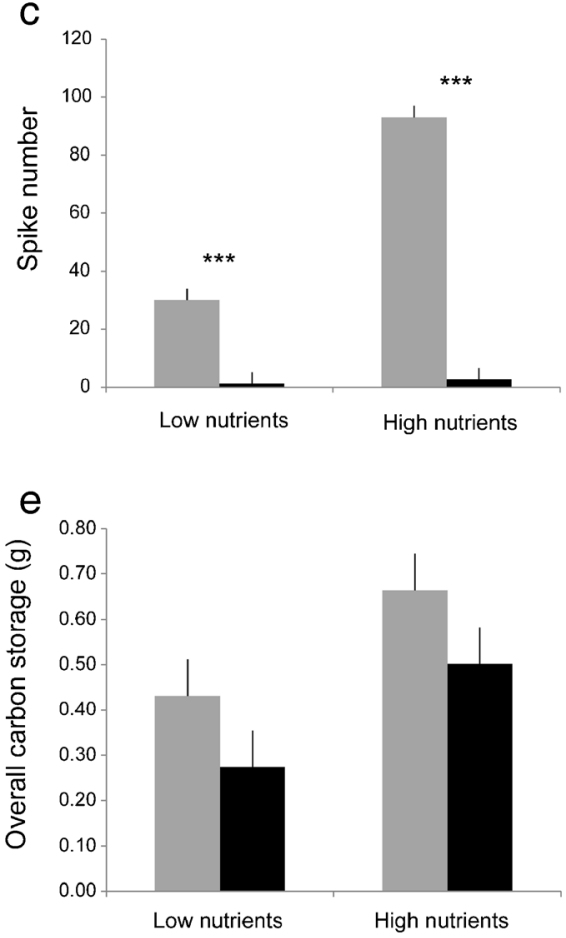

g

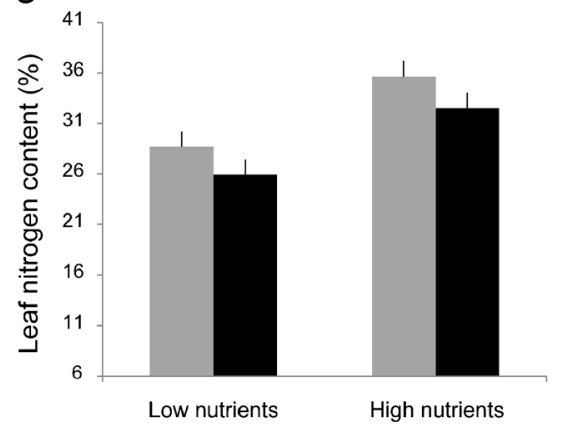

g b

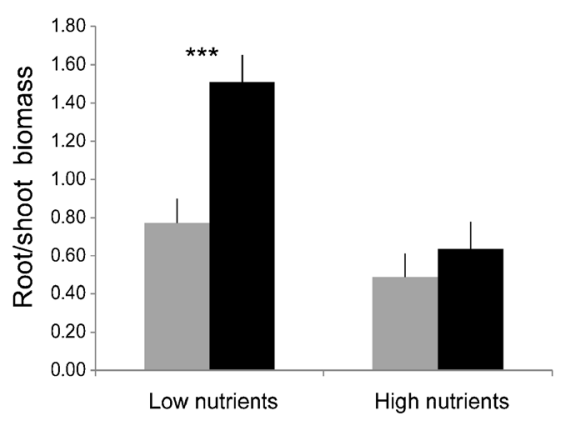

d

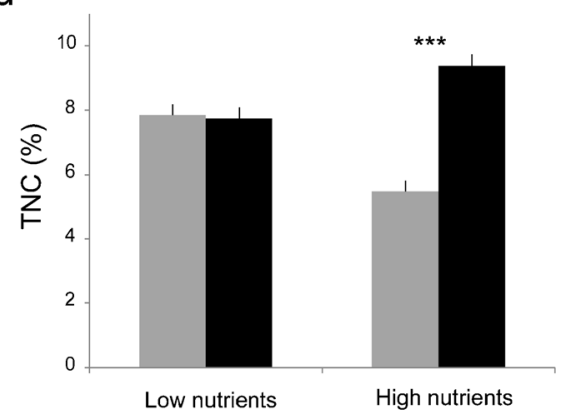

f

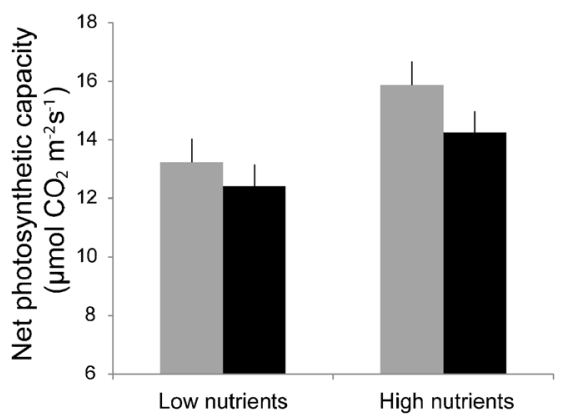


intensive photosynthesis in damaged versus undamaged plants reported by other authors (e.g. Trumble et al. 1993; Suwa and Maherali 2008) was not observed in our experiment.

The lack of significant differences in both biomass compensation and total carbohydrate storage between different nutrient levels in our study is not in accord with the "limiting resource framework" proposed by Banta et al. (2010). Moreover, although concentrations of carbohydrates in roots in our study seem to be consistent with the "limiting resource framework," this pattern can highly probably be ascribed to the limited ability to invest resources in flowering and production of seeds.

\section{Implications for Recurrently Disturbed Ecosystems}

The "limiting resource framework", which focuses on the relationship between nutrient availability and responses to apical meristem damage, predicts that nutrients promote resprouting of plants (Banta et al. 2010). On the other hand, as predicted by a model that takes into account not only habitat productivity but also disturbance frequency and intensity, in some scenarios of recurrent disturbance (e.g. by fire), it is in nutrient-poor rather than nutrient-rich environments that a resprouting rather than a seeding strategy is favoured (Bellingham and Sparrow 2000). More generally, according to the resprouter-seeder concept, resprouters invest limited resources in storage organs and bud bank formation (Pate et al. 1990, 1991; Bowen and Pate 1993; Bell and Ojeda 1999; Verdaguer and Ojeda 2002; Olano et al. 2006; Palacio et al. 2007; but see Cruz et al. 2002, 2003), which reduces their overall growth (Bond and Midgley 2003; but see Chew and Bonser 2009) or fecundity (Lamont 1985; Verdú 2000; Bond and Midgley 2001). Such allocation costs may therefore limit the occurrence of the resprouting strategy in highly competitive environments in which seeders are present.

It would thus seem that in certain scenarios, the limiting resource model and the resprouter-seeder concept would yield contradictory predictions. However, this contradiction seems to be largely overlooked, perhaps in part because the limiting resource framework was essentially constructed to consider damage from herbivory rather than severe recurrent disturbances such as those inflicted by fire. The contrasting expectations of the two concepts could be explained by the fact that woody plants are major players in fire-prone areas whereas perennial herbs dominate pastures. While not all woody plants possess belowground regenerative organs and differ therefore in their capacity to resprout when all their aboveground biomass is lost, all perennial herbs can resprout and only the degree of their compensation depends on intrinsic and extrinsic conditions. This seeming difference can disappear, however, when we consider herbaceous vegetation after a more severe disturbance which removes the upper soil layer. Under such conditions, not all perennial herbs have their available regenerative organs deep enough to allow resprouting, so they face the same problems as woody plants in fire-prone areas (Klimešová and Klimeš 2003). Resprouting and compensatory capacity is therefore affected by an interplay of plant morphological traits (bud bank location) and by limiting resources (nutrients, carbon etc.; Huhta et al. 2003; Vesk and Westoby 2004).

According to our previous results obtained from pot experiments, the relative abundance of resprouting (i.e. the percentage of resprouted individuals) is usually 
higher under nutrient-poor conditions (Latzel and Klimešová 2009; Martínková et al., unpubl. data) whereas the degree of biomass and seed compensation improves with high nutrient availability (Martínková et al. 2008; Latzel and Klimešová 2009). Although the results were obtained without considering competition, which might affect the ability of damaged plants to tolerate disturbance (Chew and Bonser 2009), it seems that the higher relative frequency of resprouting in nutrient-poor conditions but greater compensation under nutrient-rich conditions after severe disturbance is a general pattern, at least in our study system. This might be caused by plant physiological processes in which nutrient-poor conditions promote formation of adventitious buds whereas nutrient-rich conditions provide important resources for regrowth.

\section{Conclusion}

Although we did not observe a direct positive effect of soil nutrients on disturbance tolerance as proposed by the "limiting resource framework" (Banta et al. 2010), the consideration of carbon storage indicated that plants respond differently to damage under conditions differing in nutrient availability. Our results suggest that when studying responses of perennial plants to damage, it is necessary to consider not only biomass and seed production but also replenishment of reserve meristems (bud bank) and stored carbohydrates. Moreover, we also suggest that other factors such as time available for regeneration before the end of the growing season and physiological signals involved in the regulation of flowering can significantly affect plant damage tolerance, so they should be taken into account when interpreting observed patterns.

Acknowledgement This study was financially supported by the Czech Science Foundation, grant No. P505/10/P173, GA 526/09/0963 and the institutional long-term research development project No. RVO 67985939. We are grateful to two anonymous reviewers for their valuable comments on the manuscript and to Jonathan Rosenthal who offered helpful comments and significantly improved our English. We also thank Michaela Latzel for her work on the figures.

\section{References}

Banta JA, Stevens MHH, Pigliucci N (2010) Comprehensive test of the 'limiting resources' framework applied to plant tolerance to apical meristem damage. Oikos 119:359-369

Bartoš M, Janeček Š, Klimešová J (2011) Effect of mowing and fertilization on biomass and carbohydrate reserves of Molinia caerulea at two organizational levels. Acta Oecol 37:299-306

Bell L, Ojeda E (1999) Underground starch storage in Erica species of the Cape Floristic Region: differences between seeders and resprouters. New Phytol 144:143-152

Bellingham PJ, Sparrow AD (2000) Resprouting as a life history strategy in woody plant communities. Oikos 89:409-416

Bond WJ, Midgley JJ (2001) The persistence niche: ecology of sprouting in woody plants. Trends Ecol Evol 16:45-51

Bond WJ, Midgley JJ (2003) The evolutionary ecology of sprouting. Int J Pl Sci 164:103-114

Bowen BJ, Pate JS (1993) The significance of root starch in postfire shoot recovery of the resprouter Stirlingia latifolia R. Br. (Proteaceae). Ann Bot (Oxford) 72:7-16

Budzianowska A, Skrzypczak L, Budzianowski J (2004) Phenylethanoid glucosides from in vitro propagated plants and callus cultures of Plantago lanceolata. Pl Med 70:834-840 
Canadell J, López-Soria L (1998) Lignotuber reserves support regrowth following clipping of two Mediterranean shrubs. Funct Ecol 12:31-38

Chew SJ, Bonser SP (2009) The evolution of growth rate, resource allocation and competitive ability in seeder and resprouter tree seedlings. Evol Ecol 23:723-735

Clarke PJ, Knox KJE, Wills KE, Campbell M (2005) Landscape patterns of woody plant response to crown fire: disturbance and productivity influence sprouting ability. $J$ Ecol 93:544-555

Clarke PJ, Lawes MJ, Midgley JJ, Lamont BB, Ojeda F, Burrows GE, Enright NJ, Knox KJE (2013) Resprouting as a key functional trait: how buds, protection and resources drive persistence after fire. New Phytol 197:19-35

Cruz A, Pérez B, Moreno JM (2003) Plant stored reserves do not drive resproutingof the lignotubers shrub Erica australis. New Phytol 157:251-261

Cruz A, Pérez B, Quintana JR, Moreno JM (2002) Resprouting in the Mediterranean-type shrub Erica australis affected by soil resource availability. J Veg Sci 13:641-650

Dalgleish HJ, Hartnett DC (2006) Below-ground bud banks increase along a precipitation gradient of the North American Great Plains: a test of the meristem limitation hypothesis. New Phytol 171:81-89

Ferraro DO, Oesterheld M (2002) Effect of defoliation on grass growth. A quantitative review. Oikos 98:125-133

Huhta AP, Hellström K, Rautio P, Tuomi J (2003) Grazing tolerance of Gentianella amarelle and other monocarpic herbs: why is tolerance highest at low damage levels? Pl Ecol 166:49-61

Hutchings MJ, John EA (2004) The effects of environmental heterogeneity on root growth and root/shoot partitioning. Ann Bot (Oxford) 94:1-8

Janeček Š, Patáčová E, Klimešová J (2014) Effects of fertilization and competition on plant biomass allocation and internal resources: does Plantago lanceolata follow the rules of economic theory? Folia Geobot (this issue) doi:10.1007/s12224-013-9161-5

Janeček Šs, Lanta V, Klimešová J, Doležal J (2011) Effect of abandonment and plant classification on carbohydrate reserves of meadow plants. Pl Biol 13:243-251

Klimešová J, Klimeš L (2003) Resprouting of herbs in disturbed habitats: is it adequately described by Bellingham-Sparrow's model? Oikos 103:225-229

Klimešová J, Klimeš L (2006) CLO-PLA3 - a database of clonal growth architecture of Central-European plants. Available at: http://clopla.butbn.cas.cz

Lamont BB (1985) The comparative reproductive biology of three Leucospermum species (Proteaceae) in relation to fire responses and breeding system. Austral J Bot 33:139-145

Latzel V, Klimešová J (2009) Fitness of resprouters versus seeders in relation to nutrient availability in two Plantago species. Acta Oecol 35:541-547

Latzel V, Klimešová J (2010) Year-to-year changes in expression of maternal effects in perennial plants. Basic Appl Ecol 11:702-708

Latzel V, Malíková L, Klimešová J (2011) Compensatory growth of Euphorbia peplus regenerating from a bud bank. Botany 89:313-321

Latzel V, Hájek T, Klimešová J, Gómez S (2009) Nutrients and disturbance history in two Plantago species: maternal effects as a clue for observed dichotomy between resprouting and seeding strategies. Oikos 118:1669-1678

Latzel V, Klimešová J, Hájek T, Gómez S, Šmilauer P (2010) Maternal effects alter progeny’s response to disturbance and nutrients in two Plantago species. Oikos 119:1700-1710

Martínková J, Klimešová J, Mihulka S (2004) Resprouting after disturbance: an experimental study with short-lived monocarpic herbs. Folia Geobot 39:1-12

Martínková J, Klimešová J, Mihulka S (2008) Compensation of seed production after severe injury in the short-lived herb Barbarea vulgaris. Basic Appl Ecol 9:44-54

Olano JM, Menges ES, Martínez E (2006) Carbohydrate storage in five resprouting Florida scrub plants across a fire chronosequence. New Phytol 170:99-106

Palacio S, Maestro M, Montserrat-Martí G (2007) Relationship between shoot-rooting and root-sprouting abilities and the carbohydrate and nitrogen reserves of Mediterranean dwarf shrubs. Ann Bot (Oxford) 100:865-874

Pate JS, Meney KA, Dixon KW (1991) Contrasting growth and morphological characteristics of firesensitive (obligate seeder) and fire-resistant (resprouter) species of Restionaceae (S. hemisphere restiads) from south-western Western Australia. Austral J Bot 39:505-525

Pate JS, Froend RH, Bowen BJ, Hansen A, Kuo J (1990) Seedling growth and storage characteristics of seeder and resprouter species of Mediterranean-type ecosystems of S.W. Australia. Ann Bot (Oxford) 65:585-601 
Puijalon S, Piola F, Bornette G (2008) Abiotic stresses increase plant regeneration ability. Evol Ecol 22:493-506

Richards JH, Caldwell MM (1985) Soluble carbohydrates, concurrent photosynthesis and efficiency in regrowth following defoliation, a field-study with Agropyron species. J Appl Ecol 22:907-920

Schutz AEN, Bond WJ, Cramer MD (2009) Juggling carbon: allocation patterns of a dominant tree in a fire-prone savanna. Oecologia 160:235-246

Sosnová M, Klimešová J (2009) Life-history variation in the short-lived herb Rorippa palustris: the role of carbon storage. Acta Oecol 35:691-697

Suwa T, Maherali H (2008) Influence of nutrient availability on the mechanisms of tolerance to herbivory in an annual grass, Avena barbata (Poaceae). Amer J Bot 95:434-440

Tolsma AD, Tolhurst KG, Read SM (2010) Effects of fire, post-fire defoliation, drought and season on regrowth and carbohydrate reserves of alpine snowgrass Poa fawcettiae (Poaceae). Austral J Bot 58:157-168

Trumble JT, Kolodney-Hirsh DM, Ting IP (1993) Plant compensation for arthropod herbivory. Annual Rev Entomol 38:93-119

Verdaguer D, Ojeda F (2002) Root starch storage and allocation patterns in seeder and resprouter seedlings of two Cape Erica (Ericaceae) species. Amer J Bot 89:1189-1196

Verdú M (2000) Ecological and evolutionary differences between Mediterranean seeders and resprouters. $J$ Veg Sci 11:265-268

Vesk PA, Westoby M (2004) Sprouting by plants: the effects of modular organization. Funct Ecol 18:939945

White LM (1973) Carbohydrate reserves of grasses: a review. J Range Managem 26:13-18

Received: 31 December 2011 / Revised: 21 January 2013 / Accepted: 23 January 2013 /

Published online: 14 July 2013 